\title{
ESTRATÉGIAS DE REPRODUÇÃO E MODOS DE DOMINAÇÃO*
}

\section{REPRODUCTION STRATEGIES AND MODES OF DOMINATION}

Pierre Bourdieu

Uma das questões mais fundamentais acerca do mundo social é saber por que e como esse mundo dura, persevera no ser, como se perpetua a ordem social, isto é, o conjunto das relações de ordem que o constituem. Para responder realmente a essa pergunta, é preciso recusar tanto a visão "estruturalista”, que postula que as estruturas, carregando em si o princípio de sua própria perpetuação, reproduzem-se com a colaboração obrigatória de agentes submetidos às suas coerções, quanto a visão interacionista ou etnometodológica (ou, mais amplamente, marginalista), para a qual o mundo social é produto dos atos de construção operados pelos agentes em cada momento, numa espécie de "criação continuada”. Em outras palavras, é preciso recusar esta pergunta: os sinais de submissão que os subordinados enviam continuamente a seus superiores alimentam e realimentam incessantemente a relação de dominação ou se, ao contrário, a relação objetiva de dominação impõe os sinais de submissão? Na verdade, o mundo social é dotado de um conatus, como diziam os filósofos clássicos,

\footnotetext{
* Este texto é a transcrição do curso do Collège de France ministrado em Göttingen, em 23 de setembro de 1993. As comunicações apresentadas após esse curso no seminário da Mission historique française na Alemanha, organizada por Patrice Veit e Olivier Christin, serviram de base a este número de Actes de la recherche en sciences sociales. Outros trabalhos apresentados nesse seminário serão publicados posteriormente, sobretudo os artigos de Alf Lüdke, Jurgen Schlumbohm, Hans Medick e outros pesquisadores do Max Planck Institutfür Geschichte, assim como um quadro global da história social na Alemanha, com contribuições de Carola Lipp e Étienne François, dentre outras. Tradução de Patrícia C. R. Reuillard (UFRGS). Revisão técnica de Igor Gastal Grill e Rodrigo da Rosa Bordignon. Originalmente publicado na Actes de la recherche en sciences sociales. V. 105, n. ${ }^{\circ} 1,1994.0$ comitê editorial optou por manter a normalização do original. A publicação da versão em português foi autorizada pela equipe editorial do periódico.
} 
uma tendência a perseverar no ser, um dinamismo interno, inscrito nas estruturas objetivas e, ao mesmo tempo, nas estruturas “subjetivas", nas disposições dos agentes, e continuamente mantido e sustentado por ações de construção e de reconstrução das estruturas, que dependem, em seu princípio, da posição que aqueles que as realizam ocupam nas estruturas. Toda sociedade repousa na relação entre os dois princípios dinâmicos, que têm importância desigual conforme as sociedades: um se insere nas estruturas objetivas, sobretudo na estrutura da distribuição do capital e nos mecanismos que tendem a garantir sua reprodução; o outro nas disposições (à reprodução). É na relação entre esses dois princípios que os diferentes modos de reprodução se definem, particularmente as estratégias de reprodução que os caracterizam.

Antes de entrar nas abstrações, inevitáveis, da tentativa de formalização ou, se isso não for enfático demais, de axiomatização que vou propor a vocês, eu gostaria de lembrar rapidamente como surgiram e se desenvolveram as reflexões teóricas que me levaram a construir o conceito de sistema de estratégias de reprodução. Parece-me necessário, sobretudo para ouvintes que pertencem majoritariamente a uma outra disciplina - a História - e a uma outra tradição intelectual nacional, explicitar o contexto histórico no qual - e contra o qual - fui levado a conceber toda uma classe de ações como estratégias, e não como estabelecimento de regras, objetivamente orientadas para a reprodução deste corpo social - a família ou a "casa" - que constitui um sistema.

Porém, mais do que os mal-entendidos inerentes à comunicação interdisciplinar e internacional, temo aqueles que podem advir da desrealização causada pela formalização. Por exemplo, muitas vezes me ocorreu que o pensamento de Max Weber padeceu muito com as leituras teoricistas favorecidas pelas tentativas de formalização que ele apresentou, no final de sua vida, em Wirtschaftund und Gesellschaft [Economia e Sociedade], e que várias deformações de sua obra teriam sido provavelmente evitadas se muitos de seus leitores (principalmente Talcott Parsons) tivessem tido uma visão mais exata do contexto histórico específico (do espaço dos possíveis científicos) no qual ela se constituíra e das pesquisas históricas em que se sustentara. Além disso, como os princípios de erro contra os quais eles foram construídos continuam em vigor, os conceitos mais rigorosamente controlados permanecem expostos a empregos distraídos e superficiais que, como acontece geralmente com noções como capital cultural ou capital simbólico, tendem a destruir o poder de ruptura que eles contêm.

Não é fácil reconstituir de modo exato o espaço dos possíveis teóricos quando comecei a me interessar, nos anos sessenta - através da Cabília, no norte da Argélia, e da região francesa do Béarn, no noroeste dos Pireneus -, pela lógica das trocas matrimoniais e das práticas sucessórias. Mas é certo que esse espaço era dominado pela visão estruturalista que, graças à ambiguidade da noção de regra, podia dar a feição de uma revolução teórica a uma restauração do juridismo que, desde a origem, assombrara as pesquisas etnológicas em matéria de teorias do parentesco, como bem mostrou Louis Dumont, mas também e sobretudo em matéria de teorias da devolução dos bens. Típica dessa visão é a leitura que Emmanuel Le Roy Ladurie fará dos trabalhos de Jean Yver e que leva a definir áreas geográficas nas quais se impõem normas sucessórias inflexíveis que não permitem 
ajustes ou negociações ${ }^{1}$. Sem dúvida porque eu participava desse clima teórico, incontestavelmente ligada ao prestígio extraordinário da obra de Claude Lévi-Strauss, especialmente As Estruturas Elementares do Parentesco, aos olhos de todos os pesquisadores em Ciências Sociais, eu havia tentado, em um primeiro trabalho sobre o caso do Béarn, construir um modelo relacionando trocas matrimoniais e tradições de sucessão ${ }^{2}$.

Porém, um estudo mais aprofundado de casamentos concretos, em particular de casos de alianças assimétricas de casamento, tanto na Cabília quanto em Béarn, levou-me aos poucos a questionar a visão estruturalista, que talvez devesse um tanto de sua sedução à tendência a reduzir o funcionamento social a uma espécie de mecanismo de relógio e a fazer do etnólogo que mostrava esse mecanismo uma espécie de Deus relojoeiro, externo e superior à sua criação. De fato, ficava claro para mim que, tanto no caso da Cabília quanto no do
Béarn, a norma oficial, o "casamento preferencial" com a prima paralela ou o direito de progenitura, era apenas uma das imposições, mas não a mais imperativa, com que contavam os agentes para conceber suas estratégias de sucessão ou de matrimônio. Era preciso, então, abandonar a visão altiva e o "olhar distanciado" que caracterizavam a visão estruturalista para se colocar, por meio de uma mudança radical de "paradigma” (no sentido do Kuhn), simbolizada pelo apelo à noção de estratégia, na própria prática, no ponto de vista dos agentes - o que não quer dizer, como Lévi-Strauss às vezes sugeriu, na sua consciência, por meio de uma regressão a uma fenomenologia subjetivista, servindo de fundamento a uma visão ingenuamente "espontaneísta" da ordem social ${ }^{3}$. Essa mudança da relação com os agentes - menos distante - e com a prática - menos "intelectualista" - implicava uma transformação profunda do olhar lançado sobre as práticas, isto é, a construção de uma teoria da prática fundada em

1. Cf. J. Yver, Égalité entre héritiers et Exclusion des enfants dotés. Essai de géographie coutumière, Paris, Sirey, 1966. E. Le Roy Ladurie, "Structures familiales et cotumes d'héritage en France au XVI tème de la coutume”, Annales ESC, no 4-5, 1972, p. 825-846, retomado em Le Territoire de l'historien, Paris, Gallimard, p.222-251.

2. Cf. P. Bourdieu, “Célibat et condition paysanne”, Études rurales, nºs 5-6, avril-septembre 1962, p.32-136. Sobre esse trabalho e sua continuidade e aperfeiçoamento na tradição etnológica, ver o número especial da revista Études rurales: la terre, succession et héritage, 1988, p. 110-113.

3. A noção de estratégia tal como empreguei tinha por virtude primeira registrar as restrições estruturais que pesam sobre os agentes (contra certas formas de individualismo metodológico) ao mesmo tempo que a possibilidade de respostas ativas a essas restrições (contra certa versão mecanicista do estruturalismo). Como indica a metáfora do jogo, essas restrições estão inscritas, no essencial, no capital disponível (em seus diferentes tipos), isto é, na posição ocupada por uma determinada unidade na estrutura da distribuição desse capital e, portanto, na relação de forças com outras unidades. Em ruptura com o uso dominante da noção, que considera as estratégias como intenções conscientes e a longo prazo de um agente individual, eu empregava esse conceito para designar os conjuntos de ações ordenadas em vista de objetivos em um prazo mais ou menos longo e não necessariamente estabelecidos como tais, que são produzidos pelos membros de um coletivo tal como o lar (Cf. P. Bourdieu, Les stratégies matrimoniales dans le système de reproduction", Annales, 4-4, juillet-octobre 1972, p. 1105-1127; Cl. Lévi-Strauss, "L'ethnologie et l'histoire”, Annales ESC, 6, novembre-décembre 1983, p. 1217-1231 ; P. Bourdieu, “De la règle aux stratégies", in Choses dites, Paris, Éd. De Minuit, p.75-93. 
uma teoria reflexiva do olhar teórico (ou do "scholastic bias"), que acarretava, por sua vez, uma transformação profunda do modo de investigar as estratégias matrimoniais ou de sucessão. Por exemplo, no caso da Cabília, consegui mostrar, com Abdelmalek Sayad, que o nome próprio, esse elemento fundamental do capital simbólico, era a aposta de estratégias extremamente complexas tanto entre os ascendentes quanto entre os descendentes - estratégias que outros também observaram em lugares e tradições muito diferentes ${ }^{4}$. Falar de aposta significa abandonar a lógica mecanicista da estrutura pela lógica dinâmica e aberta do jogo e se obrigar a considerar, para compreender cada novo lance jogado, toda a série dos lances anteriores, tanto em matéria matrimonial quanto sucessória. Em suma, significa obrigar a reintroduzir o tempo - que Leibniz definia como “a ordem das sucessões” - e também, à maneira dos próprios agentes, o conjunto (ou o sistema) das estratégias de todo tipo, matrimoniais e sucessórias, mas também econômicas, educativas, etc., que estão na base do jogo e do poder sobre o jogo e, através deste, de toda nova estratégia.

As propostas teóricas que vou tentar expor se apoiam, portanto, em toda uma série de análises históricas muito precisas das estratégias empregadas, em contextos muito distintos, por agentes muito diferentes - camponeses da Cabília ou franceses da região do Beárn, industriais preocupados em garantir a perpetuação de sua empresa, ou empregados desejosos de transmitir seu capital cultural, assegurando sua conversão em capital escolar -, e através das quais se realiza o conatus da unidade doméstica. Assim como as análises etnológicas que fiz do Béarn ou da Cabília orientaram minhas pesquisas sobre as estratégias educativas que as diferentes categorias sociais aplicam, em todas as sociedades avançadas atuais, para reproduzir sua posição no espaço social, essas análises sociológicas também me permitiram compreender melhor as transformações das estratégias matrimoniais das sociedades camponesas, determinadas pela unificação do mercado dos bens simbólicos e pela transformação profunda do sistema dos mecanismos de reprodução ligada ao aumento extraordinário do peso do sistema escolar ${ }^{5}$.

Pode-se apresentar uma espécie de quadro das grandes classes de estratégias de reprodução (engendradas por essas disposições) presentes em todas as sociedades, mas com pesos diferentes (conforme o grau de objetivação do capital sobretudo) e formas que variam conforme a natureza do capital a ser transmitido e o estado dos mecanismos de reprodução disponíveis (por exemplo, as tradições de sucessão). Essa construção teórica permite restaurar, na análise científica, a unidade de práticas, quase sempre apreendidas de modo disperso e separado por ciências diferentes (Direito, Demografia, Economia, Sociologia).

Ainda que, na prática, as estratégias de reprodução sejam interdependentes e mescladas, pode-se distribuí-las em algumas

4. P. Bourdieu, Esquisse d'une théorie de la pratique, Génève, Droz, 1966, p.82-83, 133-137; Christiane Kalpisch-Zuber, La Maison et le Nom, stratégies et rituels dans l'Italie de la Renaissance, Paris, École des hautes études en sciences sociales, 1990.

5. Cf. P. Bourdieu, "Reproduction interdite. La dimension symbolique de la domination économique", Études rurales, $\mathrm{n}^{\text {os }}$ 113-114, janvier-juin 1989, p.15-36 ; "Le patronat", Actes de la recherche en sciences sociales, no 21, mars-avril, 1978, p. 3-82. 
grandes classes. Entre as estratégias de investimento biológico, as mais importantes são as de fecundidade e as profiláticas. As primeiras são estratégias de longo prazo, que envolvem todo o futuro da linhagem e de seu patrimônio e visam a controlar a fecundidade, isto é, aumentar ou reduzir o número dos filhos e, assim, a força do grupo familiar, mas também o número dos pretendentes potenciais ao patrimônio material e simbólico: conforme os meios disponíveis, elas podem optar por vias diretas, como as técnicas de limitação dos nascimentos, ou indiretas, como o casamento tardio ou o celibato, que tem a dupla vantagem de impedir a reprodução biológica e de excluir (ao menos na prática) da herança (esta é a função da orientação de alguns dos filhos para o sacerdócio nas famílias aristocráticas ou burguesas no Antigo Regime, ou do celibato dos mais novos em algumas tradições camponesas que favorecem o primogênito). As estratégias profiláticas se destinam a manter o patrimônio biológico, garantindo os cuidados contínuos ou descontínuos para manter a saúde ou afastar a doença e, mais geralmente, assegurando uma gestão racional do capital corporal.

As estratégias sucessórias visam a garantir a transmissão do patrimônio material entre as gerações com o mínimo de desfalque possivel dentro das possibilidades oferecidas pelo costume ou pelo direito - nem que seja recorrendo a todos os artifícios e subterfúgios disponíveis nos limites do direito e a todas as regalias (como a transmissão direta e invisível de bens líquidos ou de objetos). Essas estratégias se especificam conforme o capital a transmitir e, portanto, conforme a composição do patrimônio.

As estratégias educativas - que têm nas estratégias escolares das famílias ou dos filhos escolarizados um caso particular - são de investimento de longo prazo e não necessariamente percebidas como tais, e não se reduzem, como crê a economia do "capital humano", apenas à sua dimensão econômica, ou mesmo monetária: de fato, elas tendem acima de tudo a produzir agentes sociais dignos e capazes de receber a herança do grupo, ou seja, de retransmiti-la, por sua vez, ao grupo. É o caso notadamente das estratégias "éticas", que visam a inculcar a submissão do indivíduo e de seus interesses ao grupo e seus interesses superiores e que, por essa razão, preenchem uma função fundamental: garantem a reprodução da família, ela mesma "sujeito" das estratégias de reprodução.

As estratégias de investimento econômico, no sentido amplo do termo, são orientadas para a perpetuação ou para o aumento dos diferentes tipos de capital. Às estratégias de investimento econômico, em sentido estrito, deve-se acrescentar as de investimento social, orientadas para a instauração ou para a manutenção de relações sociais diretamente utilizáveis ou mobilizáveis, a curto ou a longo prazo, isto é, para sua transformação em obrigações duradouras, subjetivamente percebidas (sentimentos de reconhecimento, de respeito, etc.) ou institucionalmente garantidas (direitos) e, portanto, em capital social e em capital simbólico. Tal transformação é operada pela alquimia da troca - de dinheiro, de trabalho, de tempo, etc. - e por todo um trabalho específico de manutenção das relações. As estratégias matrimoniais, caso particular das anteriores, devem garantir a reprodução biológica do grupo sem ameaçar sua reprodução social com matrimônios desiguais e assegurar, pela aliança com um grupo ao menos equivalente em todos os aspectos socialmente pertinentes, a manutenção do capital social.

As estratégias de investimento simbólico são todas as ações que visam a conservar 
e a aumentar o capital de reconhecimento (nos diferentes sentidos), favorecendo a reprodução dos esquemas de percepção e de apreciação mais propícios às suas propriedades e produzindo ações capazes de serem apreciadas positivamente conforme essas categorias (por exemplo, mostrar força para não precisar usá-la). As estratégias de sociodiceia, caso particular de investimento simbólico, visam a legitimar a dominação e seu fundamento (isto é, a espécie de capital sobre o qual ela repousa), naturalizando-os.

As estratégias de reprodução têm, por princípio, não uma intenção consciente e racional, mas as disposições do habitus, que tende espontaneamente a reproduzir as condições de sua própria produção. Por dependerem das condições sociais que originam o habitus - ou seja, do volume e da estrutura do capital possuído pela família (e de sua evolução no tempo) nas distintas sociedades -, elas tendem a perpetuar sua identidade, que é diferença, mantendo variações, desvios e relações de ordem e concorrendo assim, na prática, para a reprodução de todo o sistema das diferenças constitutivas da ordem social ${ }^{6}$. As estratégias de reprodução engendradas pelas disposições à reprodução inerentes ao habitus podem ser acompanhadas de estratégias conscientes, individuais e às vezes coletivas, que, quase sempre inspiradas pela crise do modo de reprodução estabelecido, não contribuem necessariamente para a realização dos fins a que visam.

As estratégias de reprodução constituem um sistema e, por essa razão, estão na base de substituições funcionais e de efeitos compensatórios ligados à unidade de função. Por exemplo, as estratégias matrimoniais podem suprir aos insucessos das estratégias de fecundidade. Por se aplicarem a períodos diferentes do ciclo de vida como processo irreversível, as diferentes estratégias de reprodução são também cronologicamente articuladas, pois cada uma delas deve contar, em cada momento, com os resultados alcançados pela estratégia anterior ou com menor alcance temporal. Na tradição do Béarn, por exemplo, as estratégias matrimoniais dependiam diretamente daquelas de fecundidade da família, por intermédio do número e do sexo dos filhos, pretendentes potenciais a um "dote" ou a uma compensação, mas também das educativas, de cujo êxito dependia a aplicação de estratégias visando a afastar as filhas e os irmãos mais novos da herança (pelo casamento apropriado, ou pelo celibato ou emigração respectivamente), e, por fim, das estratégias propriamente econômicas, que visam, entre outras coisas, à manutenção ou ao aumento do patrimônio. Essa interdependência se estendia a várias gerações; uma família podia se impor pesados sacrifícios por muito tempo para compensar as "perdas" anteriormente necessárias para "dotar" em terras ou em dinheiro uma família numerosa demais, ou para restabelecer a posição material e sobretudo simbólica do grupo após uma aliança por matrimônio assimétrico ${ }^{7}$. As mesmas análises se aplicam às grandes famílias aristocráticas e às famílias reais, cujas estratégias

6. 0 habitus tende, de fato, a se perpetuar conforme sua determinação interna, afirmando sua autonomia em relação à situação (ao invés de se submeter à determinação direta do ambiente, como a matéria).

7. Cf. P. Bourdieu, “Célibat...", loc.cit., et "Les stratégies...", loc. cit.

8. Para outros exemplos, cf. a bibliografia de Marie-Christine Zelem, in Études rurales, n 110-112, 1988, p. 325-357, e também Kojima Hiroshi, “A demographic Evaluation of P. Bourdieu's 'Fertility Strategy”, The Journal of Population Problems, 45(4), 1990, p. 52-58. 
domésticas se tornam assuntos de Estado (guerras de sucessão, etc.) .

Uma história comparada dos sistemas de estratégias de reprodução deve levar em conta, por um lado, a composição do patrimônio a ser transmitido, ou seja, o peso relativo das diferentes espécies de capital; por outro, o estado dos mecanismos de reprodução (mercado, principalmente de trabalho; direito, sobretudo de sucessão ou de propriedade; instituição escolar e título escolar, etc.). Por exemplo, o peso determinante do capital simbólico no patrimônio dos camponeses cabilas (devido à tradição de indivisão da terra e do lugar eminente atribuído aos valores de honra e, portanto, à reputação do grupo) faz dessa sociedade uma espécie de laboratório para o estudo das estratégias de acumulação, de reprodução e de transmissão desse capital: as estratégias que envolvem a transmissão dos nomes próprios dos ancestrais prestigiosos, tais como analisei, ou a importância à primeira vista desmedida dos jogos da honra podem ser explicadas sem dúvida porque o acúmulo de capital simbólico, forma extremamente frágil e lábil de capital, representa a forma principal de acumulação ${ }^{9}$. Essas estratégias também são encontradas nos camponeses do Béarn, preocupados em conservar, aumentar e transmitir o nome e o renome da "casa”, mas são complicadas porque a terra possuída estabelece um limite para as estratégias, particularmente para o blefe autorizado pela lógica dos jogos simbólicos ${ }^{10}$. E outras restrições, principalmente jurídicas, mas também políticas, dão uma feição particular às estratégias das famílias reais ou aristocráticas, ainda que a familiaridade com aquelas das "casas" camponesas permita compreender imediatamente seu princípio ${ }^{11}$.

Porém, as diferentes estratégias de reprodução só se definem completamente se correlacionadas aos mecanismos de reprodução, institucionalizados ou não. 0 sistema das estratégias de reprodução de uma unidade doméstica depende dos ganhos diferenciais que ela pode esperar dos diferentes investimentos em função dos poderes efetivos sobre os distintos mecanismos institucionalizados (mercado econômico, escolar e matrimonial) que o volume e a estrutura de seu capital lhe asseguram. Através principalmente da estrutura das chances diferenciais de ganho objetivamente oferecidas aos seus investimentos pelos diferentes mercados sociais, impõem-se sistemas de preferências (ou de interesses) diferenciados e propensões muito diferentes a investir nos diferentes instrumentos de reprodução. Por exemplo, tanto na França quanto na Inglaterra, o longo período de transição do Estado dinástico ao Estado burocrático é marcado pela luta entre os que conhecem e reconhecem apenas as estratégias de reprodução de base familiar (os irmãos do rei), fundadas nos laços de sangue, e aqueles que invocam as estratégias de reprodução burocráticas (os ministros do rei), baseadas na transmissão escolar do capital cultural. Em nossas sociedades, onde diferentes instrumentos de reprodução estão disponíveis, a estrutura da distribuição dos poderes sobre os instrumentos de reprodução é o fator determinante do

9. Cf. P. Bourdieu, Esquisse..., op. cit.

10. Cf. P. Bourdieu, "Célibat...", loc. cit, p.

11. Cf. P. Bourdieu, "Esprits d’État”, Actes de la recherche en sciences sociales, nº 96-97,mars 1993, p.49-62. 
rendimento diferencial que os variados instrumentos de reprodução podem oferecer aos investimentos dos diferentes agentes e, assim, da reprodutibilidade de seu patrimônio e de sua posição social e, portanto, da estrutura de suas propensões diferenciais a investirem nos diferentes mercados. Já se mostrou, por exemplo, que o sistema escolar só pode contribuir para a reprodução da estrutura social, mais precisamente da estrutura da distribuição do capital cultural, destinando as crianças a uma eliminação ainda mais provável quando vêm de famílias com menos capital cultural, na medida em que essas crianças (e suas famílias) têm mais chances de ter disposições que as inclinem à auto-eliminação (como a indiferença ou a resistência aos estímulos escolares) porque estão em uma posição mais desfavorecida na estrutura da distribuição do capital cultural ${ }^{12}$.

Do mesmo modo, no campo do poder e até no campo do poder econômico, vê-se hoje a oposição entre agentes que, em função da estrutura do capital possuído, mais econômico ou mais cultural, orientam-se para estratégias de reprodução fundadas mais no investimento na economia, ou mais no investimento na escola: de um lado, nos patrões "familiares", a transmissão de um direito de propriedade hereditário inteiramente controlada pela família; do outro, a transmissão, mais ou menos garantida e controlada pelo Estado, de um poder vitalício, baseado no título escolar que, diferentemente do título de proprieda- de ou do título de nobreza, não é transmissível por herança. E, com mais frequência, a propensão a investir no sistema escolar depende do peso relativo do capital cultural na estrutura do patrimônio: à diferença dos empregados ou dos professores primários que concentram seus investimentos no mercado escolar, os patrões de empresas familiares, cujo êxito social não depende na mesma medida do êxito escolar, investem menos "interesse" e trabalho em seus estudos e não obtêm o mesmo rendimento de seu capital cultural.

As transformações da relação entre o patrimônio considerado em seu volume e sua estrutura e o sistema dos instrumentos de reprodução, com a transformação correlata das chances de ganho, tendem a acarretar uma reestruturação do sistema das estratégias de reprodução: os detentores de capital não podem manter sua posição na estrutura social senão ao preço de uma reconversão dos tipos de capital que eles detêm em outros tipos, mais rentáveis e mais legítimos em dado estado dos instrumentos de reprodução: este é o princípio, por exemplo, da reconversão de uma aristocracia fundiária em burocracia de Estado na Alemanha do século XIX.

Em universos sociais em que os dominantes precisam mudar sempre para conservar, eles tendem necessariamente a se dividir, sobretudo nos períodos de transformação rápida dos modos de reprodução, conforme o grau de reconversão de suas estratégias de reprodução: os agentes ou os grupos com mais tipos de capital que permitem recorrer

12. 0 que leva a revogar também a distinção usual entre métodos quantitativos e métodos qualitativos: não se pode realmente desmontar tais mecanismos senão fazendo simultaneamente a análise que se pode dizer qualitativa das disposições - por exemplo, os esquemas de percepção e de apreciação que os agentes individuais aplicam em sua escolha de uma disciplina - e a análise estatística das estruturas - por exemplo, as distribuições de acordo com o sexo e a origem social entre as diferentes disciplinas. 
aos novos instrumentos de reprodução, portanto, os mais inclinados e os mais aptos a se reconverter, opõem-se àqueles mais ligados à espécie de capital ameaçado (por exemplo, às vésperas da revolução de 1789, os pequenos aristocratas provincianos, sem fortuna nem cultura, opuseram-se à nobreza e à "burguesia de toga”, ou, em 1968, os professores das disciplinas mais diretamente subordinadas aos concursos de recrutamento dos professores - gramática, línguas clássicas, ou até Filosofia - opuseram-se aos professores das novas disciplinas, como as Ciências Sociais. Muitas das grandes oposições centrais dos debates ideológicos de uma época (por exemplo, hoje, nos anos 1990, as discussões sobrea "cultura”) não passam do confronto de diferentes formas da sociodiceia conservadora: aquelas que visam acima de tudo legitimar o modo de reprodução antigo, afirmando o que era evidente até então e transformando a doxa em ortodoxia, opõem-se àquelas que visam a racionalizar, no duplo sentido, a reconversão, precipitando a tomada de consciência das transformações e a elaboração das estratégias adaptadas e legitimando essas estratégias aos olhos dos "fundamentalistas".

Assim, a virtude maior da construção da noção de modo de reprodução como relação entre um sistema de estratégias de reprodução e um sistema de mecanismos de reprodução é que ela permite construir e compreender de modo unitário fenômenos que pertencem a universos sociais muito distantes, como a transmissão dos nomes próprios na Cabília e na Itália do Renascimento ${ }^{13}$, ou a política das grandes dinastias reais e a po- lítica doméstica das famílias camponesas (e acabar ao mesmo tempo com a oposição nociva entre a Sociologia, a História e a Etnologia). Mas ela não deve encobrir (por essa espécie de "etnologismo" que afetou a última Escola dos Anais) as diferenças profundas entre dois tipos de sociedades: aquelas em que as disposições à reprodução e as estratégias de reprodução que elas engendram não encontram outro apoio, nas estruturas sociais objetivas, a não ser nas estruturas familiares, instrumento maior, senão exclusivo, de reprodução, e precisam então se organizar em torno das estratégias educativas e matrimoniais; e as sociedades em que as disposições podem se apoiar nas estruturas do mundo econômico e nas estruturas de um Estado organizado. Do ponto de vista da reprodução, as mais importantes são as estruturas da instituição escolar.

As sociedades pré-capitalistas ou protocapitalistas se distinguem das sociedades capitalistas porque naquelas o capital é muito menos objetivado (e codificado) do que nestas e muito menos inscrito em instituições capazes de garantir sua própria perpetuação e de contribuir com seu funcionamento à reprodução das relações de ordem constitutivas da ordem social. Resulta que, nessas sociedades, o problema da perpetuação das relações sociais, especialmente das relações sociais de dominação, apresenta-se de modo particularmente dramático: como é possível subjugar alguém permanentemente? Como se pode instaurar relações de trabalho, de troca, etc., e particularmente relações dissimétricas de domi-

13. Cf. P. Bourdieu, Esquisse..., op. cit., p. 82-83, 133-137. Christiane Klapisch-Zuber, La Maison et le Nom, op. cit.

14. Como, quando não há recurso possível à justiça ou à polícia, se pode forçar um devedor? Como observa Renou, com frequência não há outro recurso a não ser a magia ou, mais precisamente, a maldição mágica (arma dos fracos, em geral das mulheres). 
nação, capazes de se perpetuar duradouramente, até mesmo além dos limites da vida daqueles que elas envolvem ${ }^{14}$ ? Pode-se aqui citar Marx, que opõe as sociedades cujas relações de produção assumem a forma de "relações de dependência pessoal" e as sociedades onde elas repousam na "interdependência das pessoas baseadas na dependência material" ${ }^{15}$. E, de fato, enquanto não existem estruturas objetivas tais como o mercado de trabalho (o "trabalhador livre”, no sentido de Weber) e o conjunto das instituições estatais - e desse ponto de vista, a mais importante é a instituição escolar -, os dominantes precisam se dedicar a um trabalho de criação contínua das relações sociais, reduzidas a relações pessoais. Vê-se bem isso no caso do fellah, camponês da África do Norte, e seu khammès ${ }^{16}$ : o patrão deve manter continuamente a relação por toda uma série de trocas que visam a identifıcá-la a uma relação entre parentes (ele pode até dar uma de suas filhas a um filho do khammès). Na ausência do que Sartre chamava de "violência inerte" dos mecanismos econômicos e sociais, tais como os do mercado de trabalho e da violência legítima das regras de direito, ele é obrigado a recorrer a essas formas suaves ou eufemizadas da imposição que definem a violência simbólica, sobretudo com todos os recursos do paternalismo (e que podem se associar à violência física mais brutalmente exercida, como na vingança) ${ }^{17}$.

Assim, as sociedades pré-capitalistas e protocapitalistas não oferecem as condições de uma dominação impessoal e, menos ainda, de uma reprodução impessoal das relações de dominação. Elas não dispõem da violência oculta dos mecanismos objetivos que basta deixar agir, como o mercado de trabalho ou o mercado escolar. Resulta disso que a perpetuação das relações sociais repousa quase exclusivamente nos habitus, isto é, nas disposições socialmente instituídas por estratégias metódicas de investimento educativo, que inclinam os agentes a produzir o trabalho contínuo de manutenção das relações sociais (com o trabalho simbólico de construção e de reconstrução genealógica). Portanto, do capital social e também do capital simbólico de reconhecimento proporcionado pelas trocas regradas, em particular, as trocas matrimoniais. E se as estratégias matrimoniais ocupam um lugar tão importante no sistema das estratégias de reprodução é porque a ligação matrimonial, mesmo não sendo necessariamente codificada de maneira tão rigorosa quanto levam a crer certas teorias do parentesco, revela-se como um dos instrumentos mais seguros, na maioria das sociedades (e ainda nas sociedades contemporâneas),

15. K.Marx, "Principes d'une critique de l'économie politique”, in Euvres, I, Paris, Gallimard, Pléiade, p. 210.

16. Arrendatário, na Argélia, que recebe um quinto do produto das terras que cultiva (N.T.).

17. Vê-se a simplificação da realidade histórica feita por Norbert Elias quando ele reduz a história da evolução da violência a um modelo linear de definhamento contínuo: se é verdade que os grandes modelos de evolução têm um interesse e um sentido, se deveria pelo menos registrar o fato de que, em muitas sociedades arcaicas, a violência física mais brutal (especialmente nas relações com o out group) coincide com formas altamente eufêmicas e estilizadas de violência simbólica (por exemplo, com a troca de dons), que essas formas refınadas (das quais o paternalismo é sem dúvida a sobrevivência) definharam à medida que se instaurava a violência inerte dos mecanismos do mercado de trabalho e, por fım, que, nas sociedades economicamente avançadas, a violência inerte encontra um corretivo nas violência suave do gerenciamento esclarecido todas as vezes que se impõe o estado da relação. 
para garantir a reprodução do capital social e do capital simbólico, enquanto protege o capital econômico.

Em sociedades cujos agentes são mantidos cada vez por mais tempo (principalmente em posição dominada) pelo efeito de mecanismos gerais, tais como aqueles que regem o mundo econômico e o mundo cultural (e se pode dizer, grosso modo, que o capital vai para o capital), o peso das estratégias matrimoniais tende globalmente a diminuir, embora ainda permaneça importante quando a família tem o controle total de um empreendimento agrícola, industrial ou comercial (nesse caso, as estratégias pelas quais a família visa garantir sua própria reprodução - estratégias de fecundidade, educativas, sucessórias e, sobretudo, matrimoniais - tendem a se subordinar às estratégias propriamente econômicas).

À medida que se constitui um campo econômico com suas próprias leis de desenvolvimento e que nele se instauram mecanismos que garantem a reprodução duradoura de sua estrutura, cuja constância o Estado contribui para garantir (como aqueles ligados à existência da moeda e que estabelecem a confiança necessária para tornar possiveis os investimentos transgeracionais), o poder direto e pessoal sobre pessoas tende a dar cada vez mais lugar ao poder sobre mecanismos assegurado pelo capital econômico ou pelo capital cultural (o título escolar).

A emergência do Estado, que organiza a concentração e a redistribuição dos diferentes espécies de capital - econômico, cultural e simbólico - acarreta uma transformação das estratégias de reprodução. Um exemplo disso, para o capital simbólico, é a passagem da honra feudal, fundada no reconhecimento dos pares e dos plebeus e que deve ser conquistada e mantida sempre, às honras burocraticamente conferidas pelo Estado. Um processo análogo é observado no domínio do capital cultural. A história das sociedades europeias é profundamente marcada pelo desenvolvimento progressivo, no campo do saber, de um modo de reprodução de componente escolar, cujos efeitos podem ser vistos primeiramente no campo do próprio poder com a passagem da lógica dinástica da "casa do rei”, baseada em um modo de reprodução familiar, à lógica burocrática da razão de Estado, baseada em um modo de reprodução escolar. Um dos fatores dessa evolução é o conjunto das contradições e dos conflitos produzidos pela coexistência, no Estado dinástico, de duas categorias de agentes - o rei e sua família de um lado e os funcionários do rei do outro -, isto é, de dois modos de reprodução e de dois poderes, um poder herdado e hereditariamente transmissível pelo sangue, fundado portanto na natureza (com o título nobiliário), e um poder adquirido e vitalício, fundado no "dom" e no mérito e garantido pelo direito (com o título escolar). 0 processo de desfeudalização que leva do Estado dinástico ao Estado burocrático pode ser descrito como um processo de desnaturalização, uma ruptura progressiva dos vínculos naturais, das lealdades primárias de base familiar. 0 Estado moderno é, primeiro, antifisis, e a lealdade ao Estado supõe uma ruptura com todas as fidelidades originárias.

0 Estado oriundo de tal processo de erradicação de qualquer vestígio de vínculos naturais - que assim mesmo sobrevivem no nepotismo e no favoritismo - favorece e garante o funcionamento, no campo do poder de Estado e também no campo do poder econômico, do modo de reprodução escolar cuja lógica específica pode ser apreendida comparando-a com o modo de reprodução 
familiar que continua se perpetuando (em uma oposição que lembra aquela que havia entre a casa do rei e os funcionários reais).

Nas grandes empresas burocráticas, o diploma deixa de ser um mero atributo estatutário (como o diploma de Direito de um patrão privado) e se torna um verdadeiro direito de entrada: a escola (sob a forma da "grande escola"18) e o corpo, grupo social que a escola produz ex nihilo aparentemente (mas, na verdade, a partir de propriedades ligadas à família), tomam o lugar da família e do parentesco. A cooptação dos colegas a partir das solidariedades da escola ou do corpo desempenha o papel do nepotismo e das solidariedades clânicas nas empresas familiares.

Toda estratégia de reprodução implica uma forma de numerus clausus porque preenche funções de inclusão e de exclusão, limitando ou o número dos produtos biológicos do corpo (mas somente a família pode fazer isso), ou o número dos indivíduos habilitados a fazer parte dele (o que pode levar a excluir uma parte dos produtos biológicos do corpo, mulheres, filhos mais novos, etc.). 0 mais importante é que, no modo de reprodução "familiar", a responsabilidade desses ajustes incumbia à família. Com o modo de reprodução de componente escolar, ao qual os patrões tecnocráticos devem sua posição, a família perde o controle das escolhas de sucessão e o poder de designar seus herdeiros. 0 que caracteriza o modo de reprodução escolar é a lógica propriamente estatística de seu funcionamento. A responsabilidade da transmissão não cabe mais a uma pessoa ou a um grupo, força- dos ou orientados pela tradição (direito de progenitura, etc.), como a transmissão familiar, mas a todo um conjunto de agentes individuais ou coletivos, cujas ações isoladas e estatisticamente associadas tendem a garantir a toda a classe privilégios que ela recusa a este ou aquele de seus elementos tomados separadamente: a Escola só pode contribuir para a reprodução da classe (no sentido lógico do termo), sacrificando alguns dos membros que seriam poupados se um modo de reprodução desse à família o pleno poder de transmissão. A contradição específica do modo de reprodução escolar reside na oposição entre os interesses da classe a que a escola serve estatisticamente e os interesses dos membros que ela sacrifica. Reside também no fato de que a superprodução, com todas as contradições que ela implica, torna-se uma constante estrutural quando, com o modo de reprodução de componente escolar, oportunidades teoricamente iguais de obter títulos escolares são oferecidas a todos os "herdeiros", meninas ou meninos, irmãos mais novos ou primogênitos, ao mesmo tempo que o acesso dos "não herdeiros" a esses títulos aumenta também (em números absolutos) e que a eliminação brutal, desde a entrada no ensino secundário, dá lugar a uma eliminação branda. Sem dúvida, a crise de 1968 é, por um lado, resultado dessa contradição.

Todavia, é preciso evitar de reduzir a oposição entre os dois modos de reprodução à oposição entre o apelo à família e o apelo à escola. $\mathrm{Na}$ verdade, trata-se mais da diferença entre uma gestão puramente familiar dos problemas de reprodução e

18. Referência às instituições de ensino superior na França que, ao contrário das universidades, recrutam seus alunos mediante concurso público e que oferecem formações de alto nível. Seus egressos preenchem, em geral,os altos escalões do governo (N.T.). 
uma gestão familiar que faz um certo uso da escola nas estratégias de reprodução. Com efeito, além de a ação de reprodução exercida pela Escola se apoiar na transmissão doméstica do capital cultural, a família continua a colocar a lógica relativamente autônoma de sua economia particular, que lhe permite acumular o capital de cada um de seus membros, a serviço da acumulação e da transmissão do patrimônio.

Outro erro possível, que consistiria em concluir, seguindo um esquema evolucionista simples, que os dois modos de reprodução correspondem a dois momentos de uma evolução inseparável daquela que leva, segundo certos autores, de um modo de dominação fundado na propriedade e nos owners [proprietários] a outro, mais racional e mais democrático, fundado na "competência" e nos managers [gerenciadores]. Na verdade, a definição do modo de reprodução legítimo é um objeto de lutas, particularmente no campo do poder econômico. E é preciso evitar considerar como o fim da história o que não passa de um estado de uma relação de forças que pode mudar. E essas lutas frequentemente assumem a forma de uma luta pelo poder sobre o Estado e sobre o poder que ele pode exercer sobre o sistema dos instrumentos de reprodução, sobretudo econômicos ou escolares.

Seria preciso analisar longamente os efeitos da transformação do modo de reprodução sobre o funcionamento da família como instância responsável pela reprodução e, inversamente, os efeitos das transformações da família (por exemplo, com a elevação do índice de divórcios) sobre o funcionamento do modo de reprodução de componente escolar. Estaria a crise da família ligada a transformações das estratégias de reprodução que tendem a reduzir a necessidade da unidade doméstica?
Muitos indícios levam a crer, no entanto, que a família burguesa continua cultivando sua integração social - condição maior de sua contribuição para a perpetuação de seu capital social e de seu capital simbólico e, assim, de seu capital econômico. Ainda estamos longe do agente econômico isolado tal como descrito pelos economistas.

Isso leva à pergunta: quem é, definitivamente, o "sujeito" das estratégias de reprodução? É certo que a família e as estratégias de reprodução estão envolvidas: sem família, não haveria estratégias de reprodução; sem estas, não haveria família (ou corpo e Stand [estamento] como quase-família). É preciso que a família exista - o que não é evidente - para que as estratégias de reprodução sejam possíveis; e destas depende a perpetuação da família, esta criação contínua. A família, na forma particular que ela assume em cada sociedade, é uma ficção social (frequentemente convertida em ficção jurídica) que se institui na realidade ao preço de um trabalho que visa a produzir duradouramente em cada um dos membros dessa unidade (principalmente pelo matrimônio como rito institucional) sentimentos que garantam tanto sua integração quanto a crença no valor dessa unidade e de sua integração. Vê-se que as estratégias educativas têm uma função fundamental, como todo trabalho simbólico, teórico (sobretudo genealógico) e prático (trocas de dons, de serviços, festas e cerimônias, etc.), que cabe particularmente às mulheres e que transforma a obrigação de amar em disposição amorosa e que tende a dotar cada um dos membros dessa unidade de um "espírito de família": esse princípio cognitivo de visão e de divisão é também princípio prático de coesão, gerador de devoções, de generosidades, de solidariedades, e de uma adesão vital à existência de um grupo familiar e de seus interesses. 
Esse trabalho de integração é ainda mais indispensável porque a família - se deve funcionar como um corpo para estar conforme - tende sempre a funcionar como um campo, com suas relações de forças físicas, econômicas e principalmente simbólicas (sobretudo ligadas ao volume e à estrutura do capital possuído pelos diferentes membros) e suas lutas pela conservação ou pela transformação dessas relações de forças. Somente ao preço de um trabalho constante, as forças de fusão (particularmente afetivas) conseguem compensar ou se opor às forças de fissão.

A unidade da família é feita para e pela acumulação e transmissão. 0 "sujeito" da maior parte das estratégias de reprodução é a família agindo como uma espécie de sujeito coletivo e não como uma simples soma de indivíduos. Para compreender as estratégias coletivas das famílias (no caso do casamento cabila, ou no da compra de uma casa na França, por exemplo), deve-se conhecer, em primeiro lugar, a estrutura e a história da relação de forças entre os diferentes agentes e suas estratégias. Mas é preciso conhecer também o volume e a estrutura do capital que elas devem transmitir, portanto, a posição de cada uma na estrutura da distribuição das diferentes espécies de capital. De fato, é essa posição que orienta as estratégias (e que é seu verdadeiro sujeito) - o que explica que, seguindo seu próprio conatus, cada uma das famílias contribui para a reprodução do espaço das posições constitutivas de uma ordem social e, portanto, para a realização do conatus inscrito nessa ordem ${ }^{19}$.

Agora se vê melhor como responder à questão do início sobre as condições da permanência da ordem social. 0 mundo social não é o universo radicalmente descontínuo de Hobbes (segundo Durkheim "Para Hobbes, é um ato de vontade que dá nascimento à ordem social e é um ato de vontade perpetuamente renovado que é seu suporte”), e que hoje propõem todos aqueles, ao buscarem restituir o lugar do "sujeito", reduzem as relações sociais, inclusive as de dominação, aos atos (sobretudo de submissão) dos agentes em cada momento. Como o universo físico, segundo Leibniz, ele/o mundo social carrega em si mesmo o princípio de seu dinamismo e de sua lógica. Esta vis insita, que é também uma lex insita, está inscrita tanto nas estruturas objetivas (e nos mecanismos que asseguram sua reprodução, como naqueles que favorecem a reprodução da distribuição do capital cultural) quanto nas estruturas do habitus ou, mais precisamente, na relação entre ambas. Ela está nas probabilidades objetivas inscritas nas tendências imanentes aos diferentes campos sociais (como tendências a produzir frequências estáveis e regularidades, frequentemente reforçadas por regras explícitas) e nas esperanças subjetivas, grosseiramente ajustadas a essas tendências, que estão inscritas nas inclinações do habitus.

19. No caso das sociedades de Estado, é preciso também conhecer a história do trabalho de institucionalização do qual a família tal como conhecemos é o desfecho. Essa coisa muito privada é, na verdade, uma questão pública, na medida em que depende de ações públicas tais como a política da habitação ou, mais diretamente, a política da família e o direito de família; garantida pelo Estado, ratificada pelo Estado, ela recebe do Estado os meios de existir e de subsistir. 


\section{RESUMO}

Para compreender como se perpetua a ordem social, devemos construir um quadro do sistema das estratégias de reprodução (matrimoniais, educativas, sucessórias, de investimento biológico, simbólico, econômico e de sociodiceia) e do sistema dos mecanismos de reprodução (mercado de trabalho, direito de sucessão, direito de propriedade, instituições escolares). Diferentes exemplos extraídos de universos sociais muito distantes, como a transmissão dos nomes próprios na região da Cabília e na Itália do Renascimento, ou a política doméstica das famílias camponesas, mostram diferenças muito profundas entre as sociedades: em algumas sociedades, as disposições à reprodução e as estratégias de reprodução que elas engendram não encontram, nas estruturas sociais objetivas, outro apoio além das estruturas familiares, instrumento maior, senão exclusivo, de reprodução e precisam se organizar em torno das estratégias educativas e matrimoniais; em outras, elas podem se apoiar nas estruturas de um Estado organizado. Do ponto de vista da reprodução, aquelas da instituição escolar são as mais importantes.

\section{PALAVRAS-CHAVE}

Estratégias de reprodução. Ordem Social. Família. Instituição Escolar. Estado.

\section{ABSTRACT}

In order to understand how the social order perpetuates itself, it is necessary to establish a table of reproduction strategies (biological investments, inheritance, education, economic investment, social investment, marriage alliances, symbolic investment and sociodicy) and of the system of reproduction mechanisms (labor market, inheritance laws, property rights, schools). Various examples taken from remote social contexts, such as the transmission of first names in Kabylia and Renaissance Italy or the domestic policy of peasant families, show the profound differences between, on the one hand, societies in which the arrangements for reproduction and the reproduction strategies they engender are wholly based, in the objectivity of social structures, on family structures, the main if not exclusive instrument of reproduction, and must therefore be organized around educational and matrimonial strategies, and, on the other hand, societies in which these strategies can also count on the structures of an organized state, the most important of which, from the point of view of reproduction, are those of the educational system.

\section{KEYWORDS}

Reproduction Strategies. Social Order. Family. Educational System. State. 
